Research Article

\title{
A Refined Model for Analysis of Beams on Two-Parameter Foundations by Iterative Method
}

\author{
Feng Yue $\mathbb{1}$ \\ School of Mechanics, Civil Engineering and Architecture, Northwestern Polytechnical University, Xi'an 710072, China \\ Correspondence should be addressed to Feng Yue; yuefeng@mail.nwpu.edu.cn
}

Received 9 February 2021; Revised 27 March 2021; Accepted 15 April 2021; Published 23 April 2021

Academic Editor: Rossana Dimitri

Copyright ( 92021 Feng Yue. This is an open access article distributed under the Creative Commons Attribution License, which permits unrestricted use, distribution, and reproduction in any medium, provided the original work is properly cited.

\begin{abstract}
It is of great significance to study the interactions between structures and supporting soils for both structural engineering and geotechnical engineering. In this paper, based on the refined two-parameter elastic foundation model, the bending problem for a finite-length beam on Gibson elastic soil is solved. The effects of axial force and soil heterogeneity on the bending behaviours and stress states of beams on elastic foundations are discussed, and the parameters of the physical model are determined reasonably. The beam and elastic foundation are treated as a single system, and the complete potential energy is obtained. Based on the principle of minimum potential energy, the governing differential equations for the beam bearing axial force on the Gibson foundation are derived, and the equations for attenuation parameters are also defined. The problem of the unknown parameters in foundation models being difficult to determine is solved by an iterative method. The results demonstrate that this calculation method is feasible and accurate, and that the applied theory is universal for the analysis of interactions between beams and elastic foundations. Both axial force and soil heterogeneity have a certain effect on the deformation and internal force of beams on elastic foundations, and the vertical elastic coefficient of foundations is mainly determined by the stiffness of the surface soil. Additionally, attenuation parameters can be obtained relatively accurately by an iterative method, and then the vertical elastic coefficient and shear coefficient can be further obtained. This research lays a foundation for the popularisation and application of the two-parameter elastic foundation model.
\end{abstract}

\section{Introduction}

With the increasing number of construction projects worldwide, many beam, plate, and shell structures have been developed, and strict standards and requirements have been proposed for structures and foundations. Foundation engineering is concealed by superstructures, which has a significant impact on the safety and economy of structures and foundations. Various quality-related accidents occur in the engineering fields, which not only cause huge losses but also make it difficult to take appropriate measures for strengthening structures. Elastic foundation beams have been widely used in structural engineering. They are the basic components in structures such as roads, bridges, and high-rise building foundations. It is critical to apply structural components in engineering practice reasonably and safely, and these concerns have attracted the attention of various academic and engineering circles [1-3]. To study the practical issues related to elastic foundation beams, many models of beams on elastic foundations have been proposed by scholars. The elastic foundations [4-8] include the Winkler foundation model, two-parameter elastic model, and elastic half-space model. The Winkler foundation model cannot consider the diffusion ability and deformation of foundations, which has great defects in theory. The elastic half-space foundation model compensates for the defects of the Winkler foundation model, but it is more complex mathematically. Therefore, the two-parameter foundation model bridging the two aforementioned models has been developed. The Vlasov foundation model is an important representative of this type of model.

The comprehensive analysis and detailed study of classical components have become important and difficult problems. Many scholars have focused on studying the interactions between structures and complex media and have obtained various theoretical systems for describing 
structures resting on foundations. Kimençe and Ergüven [9] investigated the problems of shallow spherical shells resting on Vlasov model and single-layer foundations. Hizal and Catal [10] investigated the dynamic response of axially loaded Timoshenko beams on modified Vlasov elastic foundation using the separation of variables method. Arani and Zamani [11] analysed bending behaviours of nanocomposite beams on modified Vlasov model soil, with consideration of agglomeration and distribution of carbon nanotubes. Ataman [12] analytically solved the problem of vibrations of beams on an inertial Vlasov foundation. Ozgan [13] presented the analysis of foundation plate-beam systems with transverse shear deformation by using a modified Vlasov model. Nogami and O'Neill [14] presented a method for the analysis of beams resting on a generalized two-parameter foundation. Höller et al. [15] derived a rigorous amendment of Vlasov's theory for plates on Winkler foundations, based on the principle of virtual power. Ayvaz and Daloglu [16] carried out the earthquake analysis of beams on a modified Vlasov foundation. Miao et al. [17] developed a closed-form solution for the dynamic response of an infinite Euler Bernoulli beam on a Pasternak foundation.

Many scholars have studied beams on two-parameter foundations using the direct method, Galerkin method, power series method, differential operator series method, and finite element method. However, on the one hand, the influence of axial force on foundation beams has not been considered in previous studies. In practical engineering, foundation beams are often subjected to axial forces, so it is necessary to study the influence of such forces. Additionally, designers often simplify the foundation beams to have free ends. However, in real-world scenarios, boundary conditions are not always free, and clamped support is often applied at both ends of a beam. Existing research on this type of problem is very rare.

On the other hand, the traditional Vlasov foundation model considers an elastic layer as a homogeneous and isotropic body. However, the elastic modulus of soil is considered as a linear variable along the depth of a foundation, which more closely matches its real-world behaviour. Dempsey and Li [18] studied a flexible rectangular footing on Gibson soils and analysed the rigidity required for full contact. Salgado et al. [19] presented a load-settlement analysis approach that is applicable to a pile with a circular cross section installed in multilayered elastic soil. Eisenberger and Clastornik [20] presented the two methods for the analysis of beams on variable two-parameter foundations. Medina et al. [21] analysed the influence of soil nonhomogeneity on the base shear forces of piled structures subjected to harmonic seismic waves. Ma et al. [22] developed an analytical method for the stability analysis of beams on modified Vlasov foundations subjected to lateral loads acting on the ends by using the variational principle.

Finally, the two-parameter foundation model has the advantages of simple numerical treatment and perfect theory, where two independent elastic parameters are used to represent the characteristics of foundation soils. However, the traditional Vlasov model requires the estimation of an attenuation parameter $\gamma$, which has hindered the widespread application of the two-parameter elastic foundation model. Vallabhan et al. [23] thought that the two-parameter model developed by Vlasov required the estimation of a third parameter representing the distribution of the displacements within a foundation. Jones and Xenophontos [24] presented an alternative variational formulation of Vlasov's two-parameter foundation model, which provides a rigorous theoretical basis for the current form of the vertical deformation profiles. Yang [25] developed an iterative approach that combined the advantages of a finite element method and standard finite difference technique for the analysis of plates on elastic foundations subjected to general loadings and arbitrary edge support conditions.

Regarding the foundation soil, the inhomogeneity of Gibson soil is more in line with the values in engineering practice, compared to considering the simple homogeneous and isotropic soil. In this study, finite-length beams on refined Vlasov foundations are analysed based on Gibson characteristics. The interactions between foundations and finite-length beams have been investigated systematically, and the influences of soil inhomogeneity and axial force on the bending of beams on elastic foundations have also been examined. According to the principle of energy variation, the governing equations for finite-length beams on Gibson two-parameter elastic foundations are established. Additionally, the equations that the attenuation parameters must satisfy are obtained based on variation. Finally, the attenuation parameters obtained using an iterative process are used to calculate the two characteristic parameters of the mathematical model, and relatively accurate deflections and internal forces of beams are obtained.

The novelty and importance of this paper include (1) the refined Vlasov foundation model is adopted to simulate the mechanical behaviour of the Gibson soil. (2) Using the principle of minimum potential energy, the governing equations and boundary conditions for finite-length beams resting on the refined Vlasov elastic foundations are derived. (3) Using an iterative process, the consistent values of characteristics parameters are obtained. (4) A comparative analysis between the refined Vlasov foundation and the traditional Vlasov foundation model is also carried out. (5) The effects of axial force and Gibson soil heterogeneity on the bending behaviours and stress states of beams resting on the refined Vlasov elastic foundations are discussed.

\section{Mathematical Formulation}

2.1. Gibson Foundation. As shown in Figure 1, a finite-length beam on a refined Vlasov elastic foundation is investigated. The length of the beam is $L$, the thickness is $h$, and the depth of the foundation is $H$. The axial force acting on the elastic beam is $F$. And, the uniformly distributed load is $q(x)$.

In this paper, soil inhomogeneity is considered. It is assumed that the foundation is a Gibson soil whose elasticity modulus changes linearly with depth. The elasticity modulus at the top and bottom of the foundation is denoted as $E_{s 1}$ and $E_{s 2}$, respectively, and $\mu_{s}$ is Poisson's ratio of the soil. The dimensionless parameter $\eta$ is introduced as follows: 


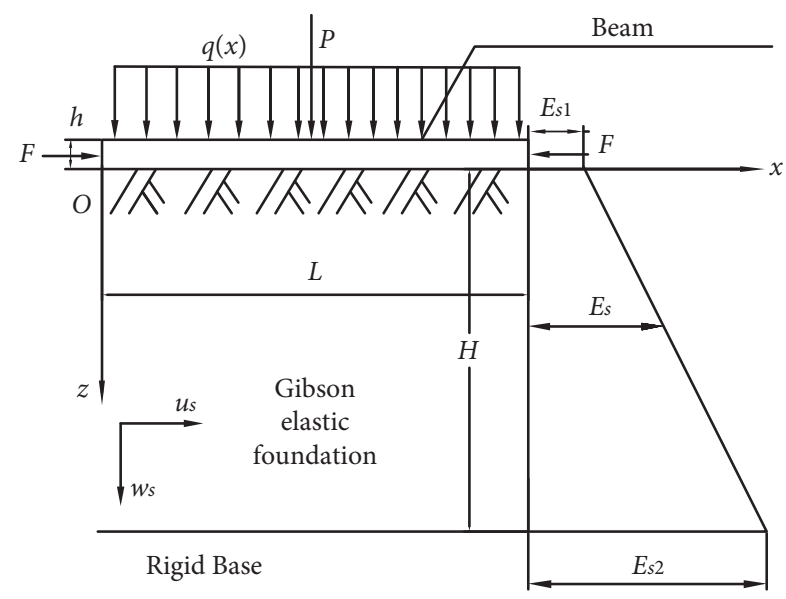

Figure 1: Finite-length beam on a Gibson two-parameter elastic foundation.

$$
\eta=\frac{E_{s 1}}{E_{s 2}} .
$$

The elasticity modulus $E_{s}$ [26] at a depth $z$ is defined as follows:

$$
E_{s}=E_{s 2}\left[\eta+(1-\eta) \frac{z}{H}\right]
$$

One can see that the soft and hard conditions of the foundation soil depend on the value of the dimensionless parameter $\eta$.

2.2. Governing Equations and Boundary Conditions. The total potential energy of the beam-foundation system is

$$
V=V_{b}+V_{s}+V_{q}
$$

where the physical quantities are the total potential energy function, deformation potential energy of the beam, deformation potential energy of the foundation, and external force potential energy, respectively. The quantities on the right side of the equation can be calculated as follows:

$$
\begin{aligned}
& V_{b}=\frac{1}{2} \int_{0}^{L} E I\left(w^{\prime \prime}\right)^{2} \mathrm{~d} x, \\
& V_{s}=\frac{b}{2} \int_{-\infty}^{+\infty} \int_{0}^{H}\left(\sigma_{x} \varepsilon_{x}+\sigma_{z} \varepsilon_{z}+\tau_{x z} \gamma_{x z}\right) \mathrm{d} z \mathrm{~d} x, \\
& V_{q}=-\int_{0}^{L} q(x) w \mathrm{~d} x-\frac{F}{2} \int_{0}^{L}\left(\frac{\mathrm{d} w}{\mathrm{~d} x}\right)^{2} \mathrm{~d} x,
\end{aligned}
$$

where $w$ is the deflection of the beam, $b$ is the beam section width, $E$ denotes the elasticity modulus of the beam, $I$ represents the moment of inertia of the beam, $\sigma_{x}, \sigma_{z}$, and $\tau_{x z}$ are the stress components of the Gibson two-parameter foundation, $\varepsilon_{x}, \varepsilon_{z}$, and $\gamma_{z x}$ are the strain components of the Gibson two-parameter foundation [27-29], $q(x)$ is external load, and EI is the flexural stiffness of the beam. The constitutive relationships are as follows.

$$
\begin{aligned}
\sigma_{x} & =\frac{E_{s}}{1-\mu_{s}}\left(\frac{\partial u_{s}}{\partial x}+\mu_{s} \frac{\partial w_{s}}{\partial z}\right), \\
\sigma_{z} & =\frac{E_{s}}{1-\mu_{s}}\left(\frac{\partial w_{s}}{\partial z}+\mu_{s} \frac{\partial u_{s}}{\partial x}\right), \\
\tau_{x z} & =\frac{E_{s}}{2\left(1+\mu_{s}\right)}\left(\frac{\partial w_{s}}{\partial x}+\frac{\partial u_{s}}{\partial z}\right), \\
\varepsilon_{x} & =\frac{\partial u_{s}}{\partial x}, \\
\varepsilon_{z} & =\frac{\partial w_{s}}{\partial z}, \\
\gamma_{x z} & =\frac{\partial w_{s}}{\partial x}+\frac{\partial u_{s}}{\partial z} .
\end{aligned}
$$

When the Gibson foundation is deformed, the horizontal displacement component $u_{s}$ is far smaller than the vertical displacement $w_{s}(x, z)$, and the settlement $w_{s}(x, z)$ of the foundation is continuously attenuated along the depth direction. Therefore, the displacement component of the foundation $u_{s}$ is equal to zero and the function $\varphi(z)$ describing the variation law of the vertical displacement $w_{s}(x, z)$ of foundation along the depth direction is introduced as

$$
w_{s}(x, z)=\bar{w}_{s}(x) \varphi(z)
$$

where $\bar{w}_{s}(x)$ is the vertical deformation of the Gibson foundation surface. The beam is in close contact with the foundation, so we have the following relational expression under the beam:

$$
w(x)=\bar{w}_{s}(x)
$$

The deformation potential energy of the Gibson foundation can be rewritten as

$$
\begin{aligned}
& V_{s}= \frac{b}{2} \int_{-\infty}^{+\infty} \int_{0}^{H}\left[\frac{E_{s}\left(1-\mu_{s}\right)}{\left(1+\mu_{s}\right)\left(1-2 \mu_{s}\right)}\left(\frac{\mathrm{d} \varphi}{\mathrm{d} z}\right)^{2} \bar{w}_{s}^{2}\right. \\
&\left.+\frac{E_{s}}{2\left(1+\mu_{s}\right)}\left(\frac{\mathrm{d} \bar{w}_{s}}{\mathrm{~d} x}\right)^{2} \varphi^{2}\right] \mathrm{d} z \mathrm{~d} x \\
& k= \frac{1}{2} \int_{-\infty}^{+\infty}\left\{k \bar{w}_{s}^{2}+G_{p}\left(\frac{\mathrm{d} \bar{w}_{s}}{\mathrm{~d} x}\right)^{2}\right\} \mathrm{d} x, \\
& \int_{0}^{H} \frac{E_{s 2} b\left(1-\mu_{s}\right)}{\left(1+\mu_{s}\right)\left(1-2 \mu_{s}\right)}\left[\eta+(1-\eta) \frac{z}{H}\right]\left(\frac{\mathrm{d} \varphi}{\mathrm{d} z}\right)^{2} \mathrm{~d} z, \\
& G_{p}=\int_{0}^{H} \frac{E_{s 2} b}{2\left(1+\mu_{s}\right)}\left[\eta+(1-\eta) \frac{z}{H}\right] \varphi^{2} \mathrm{~d} z,
\end{aligned}
$$

where $k$ and $G_{p}$ are the vertical elastic coefficient (modulus of subgrade reaction) and shear coefficient (shear modulus), respectively. 
The complete potential energy of the system is calculated as follows:

$$
\begin{aligned}
V= & \frac{1}{2} \int_{0}^{L} E I\left(w^{\prime \prime}\right)^{2} \mathrm{~d} x \\
& +\frac{b}{2} \int_{-\infty}^{+\infty} \int_{0}^{H}\left[\frac{E_{s}\left(1-\mu_{s}\right)}{\left(1+\mu_{s}\right)\left(1-2 \mu_{s}\right)}\left(\frac{\mathrm{d} \varphi}{\mathrm{d} z}\right)^{2} \bar{w}_{s}^{2}\right. \\
& \left.+\frac{E_{s}}{2\left(1+\mu_{s}\right)}\left(\frac{\mathrm{d} \bar{w}_{s}}{\mathrm{~d} x}\right)^{2} \varphi^{2}\right] \mathrm{d} z \mathrm{~d} x \\
& -\int_{0}^{L} q(x) w \mathrm{~d} x-\frac{F}{2} \int_{0}^{L}\left(\frac{\mathrm{d} w}{\mathrm{~d} x}\right)^{2} \mathrm{~d} x \\
= & \frac{1}{2} \int_{0}^{L} E I\left(w^{\prime \prime}\right)^{2} \mathrm{~d} x+\frac{1}{2} \int_{-\infty}^{+\infty}\left\{k \bar{w}_{s}^{2}+G_{p}\left(\frac{\mathrm{d} \bar{w}_{s}}{\mathrm{~d} x}\right)^{2}\right\} \mathrm{d} x \\
& -\int_{0}^{L} q(x) w \mathrm{~d} x-\frac{F}{2} \int_{0}^{L}\left(\frac{\mathrm{d} w}{\mathrm{~d} x}\right)^{2} \mathrm{~d} x .
\end{aligned}
$$

By minimising the function $V$ with respect to $w, \overline{w_{s}}$, and $\varphi$, the following equation can be obtained:

$$
\begin{array}{r}
\delta V=E I \int_{0}^{L} \frac{\mathrm{d}^{4} w}{\mathrm{~d} x^{4}} \delta w \mathrm{~d} x+\left.E I \frac{\mathrm{d}^{2} w}{\mathrm{~d} x^{2}} \delta\left(\frac{\mathrm{d} w}{\mathrm{~d} x}\right)\right|_{0} ^{L}-\left.E I \frac{\mathrm{d}^{3} w}{\mathrm{~d} x^{3}} \delta w\right|_{0} ^{L} \\
\int_{-\infty}^{0} G_{p} \frac{\mathrm{d}^{2} \bar{w}_{s 1}}{\mathrm{~d} x^{2}} \delta \bar{w}_{s 1} \mathrm{~d} x-\int_{0}^{L} G_{p} \frac{\mathrm{d}^{2} \bar{w}_{s}}{\mathrm{~d} x^{2}} \delta \bar{w}_{s} \mathrm{~d} x-\int_{L}^{+\infty} G_{p} \frac{\mathrm{d}^{2} \bar{w}_{s 2}}{\mathrm{~d} x^{2}} \delta \bar{w}_{s 2} \mathrm{~d} x+ \\
\int_{-\infty}^{0} k \bar{w}_{s 1} \delta \bar{w}_{s 1} \mathrm{~d} x+\int_{0}^{L} k \bar{w}_{s} \delta \bar{w}_{s} \mathrm{~d} x+\int_{L}^{+\infty} k \bar{w}_{s 2} \delta \bar{w}_{s 2} \mathrm{~d} x+\left.G_{p} \frac{\mathrm{d} \bar{w}_{s 1}}{\mathrm{~d} x} \delta \bar{w}_{s 1}\right|_{-\infty} ^{+}+ \\
\left.G_{p} \frac{\mathrm{d} \bar{w}_{s}}{\mathrm{~d} x} \delta \bar{w}_{s}\right|_{0} ^{L}+\left.G_{p} \frac{\mathrm{d} \bar{w}_{s 2}}{\mathrm{~d} x} \delta \bar{w}_{s 2}\right|_{L} ^{+\infty}+\int_{0}^{H}\left(-m \frac{\mathrm{d}^{2} \varphi}{\mathrm{d} z^{2}}+n \varphi\right) \delta \varphi \mathrm{d} z+\left.m \frac{\mathrm{d} \varphi}{\mathrm{d} z} \delta \varphi\right|_{0} ^{H}- \\
\int_{0}^{L} q(x) \delta w \mathrm{~d} x-\left.F \frac{\mathrm{d} w}{\mathrm{~d} x} \delta w\right|_{0} ^{L}+F \int_{0}^{L} \frac{\mathrm{d}^{2} w}{\mathrm{~d} x^{2}} \delta w \mathrm{~d} x=0,
\end{array}
$$

where $\bar{w}_{s 1}$ and $\bar{w}_{s 2}$ represent the vertical displacements of the foundation surface on the left and right sides of the beam, respectively.

$$
\begin{aligned}
& m=\int_{-\infty}^{+\infty} \frac{E_{s 2} b\left(1-\mu_{s}\right)}{\left(1+\mu_{s}\right)\left(1-2 \mu_{s}\right)}\left[\eta+(1-\eta) \frac{z}{H}\right] \bar{w}_{s}^{2} \mathrm{~d} x, \\
& n=\int_{-\infty}^{+\infty} \frac{E_{s 2} b}{2\left(1+\mu_{s}\right)}\left[\eta+(1-\eta) \frac{z}{H}\right]\left(\frac{\mathrm{d} \bar{w}_{s}}{\mathrm{~d} x}\right)^{2} \mathrm{~d} x .
\end{aligned}
$$

The governing differential equations for the beam can be derived through complex variational deduction.

$$
E I \frac{\mathrm{d}^{4} w}{\mathrm{~d} x^{4}}+\left(F-G_{p}\right) \frac{\mathrm{d}^{2} w}{\mathrm{~d} x^{2}}+k w=q(x)
$$

The foundation soil is divided into the part under the beam and the part outside the beam. The governing equations for the foundation soil outside the beam can be obtained as follows.

Left side of the beam:

$$
-G_{p} \frac{\mathrm{d}^{2} \bar{w}_{s 1}}{\mathrm{~d} x^{2}}+k \bar{w}_{s 1}=0
$$

Right side of the beam:

$$
-G_{p} \frac{\mathrm{d}^{2} \bar{w}_{s 2}}{\mathrm{~d} x^{2}}+k \bar{w}_{s 2}=0
$$

The attenuation expressions of the vertical displacement components on the surface of the foundation soil outside the beam are defined as follows: 


$$
\begin{aligned}
& \bar{w}_{s 1}=w_{s 0} e^{\alpha x}, \\
& \bar{w}_{s 2}=w_{s L} e^{-\alpha(x-L)},
\end{aligned}
$$

where $w_{s 0}$ and $w_{s L}$ are the deflections of the soil under the beam at $x=0$ and $x=L$, respectively.

$$
\alpha^{2}=\frac{k}{G_{p}},
$$

where $\alpha$ is the attenuation exponent of the Gibson twoparameter foundation model $(23,27,29)$.

Similarly, by collecting the coefficients of $\delta \varphi$, the equation for the attenuation function $\varphi(z)$ is obtained as follows:

$$
\frac{\mathrm{d}^{2} \varphi}{\mathrm{d} z^{2}}-\left(\frac{\gamma}{H}\right)^{2} \varphi=0
$$

where $\varphi(z)$ is a mode shape function defining the variation of $w_{s}(x, z)$ in the $z$ direction and $\gamma$ denotes the attenuation parameter that needs to be solved iteratively. The boundary conditions are $\varphi(0)=1$ and $\varphi(H)=0$, and the attenuation function is obtained as follows:

$$
\begin{gathered}
\varphi(z)=\frac{\sinh [\gamma(1-(z / H))]}{\sinh (\gamma)} \\
\frac{n}{m}=\left(\frac{\gamma}{H}\right)^{2}=\frac{1-2 \mu_{s}}{2\left(1-\mu_{s}\right)} \frac{\int_{-\infty}^{+\infty}(\mathrm{d} w / \mathrm{d} x)^{2} \mathrm{~d} x}{\int_{0}^{L} w^{2} \mathrm{~d} x} .
\end{gathered}
$$

Additionally, the boundary conditions of the beam with axial force on the Gibson elastic foundation can also be obtained from formula (12):

$$
\left.E I \frac{\mathrm{d}^{2} w^{2}}{\mathrm{~d} x^{2}}\right|_{0} ^{L} \frac{\mathrm{d} \delta w}{\mathrm{~d} x}-\left.E I \frac{\mathrm{d}^{3} w}{\mathrm{~d} x^{3}}\right|_{0} ^{L} \delta w+\left.G_{p} \frac{\mathrm{d} w_{\mathrm{d} x}^{L}}{0}\right|_{0} ^{L} \delta w-\left.F \frac{\mathrm{d} w_{0}^{L}}{\mathrm{~d} x}\right|_{0} ^{L} \delta w=0 .
$$

If the beam is fixed at one end and clamped at the other one end, then $\delta w=0$ and $(\mathrm{d} \delta w / \mathrm{d} x)=0$ and formula (22) naturally meets the theoretical requirements.

If the beam is simply supported at both ends, then $\delta w=$ 0 and $(\mathrm{d} \delta w / \mathrm{d} x) \neq 0$. To satisfy $(22)$, then $E I\left(\mathrm{~d}^{2} w / \mathrm{d} x^{2}\right)=0$. That is,

$$
\frac{\mathrm{d}^{2} w}{\mathrm{~d} x^{2}}=0
$$

If the two ends of the beam are free, then $\delta w \neq 0$ and $(\mathrm{d} \delta w / \mathrm{d} x) \neq 0$. To make (22) satisfy the theoretical requirements, we have

$$
\left\{\begin{array}{l}
E I \frac{\mathrm{d}^{2} w}{\mathrm{~d} x^{2}}=0 \\
-E I \frac{\mathrm{d}^{3} w}{\mathrm{~d} x^{3}}-F \frac{\mathrm{d} w}{\mathrm{~d} x}+G_{p} \frac{\mathrm{d} w}{\mathrm{~d} x}=0
\end{array}\right.
$$

\section{Numerical Methods}

3.1. Solution Methods. The following two types of boundary conditions for a finite-length beam on an elastic foundation are discussed: (1) the two ends of the beam are free and (2) the beam is fixed at one end and clamped at the other end.

First, if both ends of a finite-length beam are free and it is subjected to a uniformly distributed load $q$ and a concentrated force $P$ at $x=x_{0}$, then the deflection expression is

$$
w=\sum_{i=1}^{\infty} w_{i} \sin \frac{i \pi x}{L}+w_{0}\left(1-\frac{x}{L}\right)+w_{L} \frac{x}{L},
$$

where $w_{i}, w_{0}$, and $w_{L}$ are undetermined constants.

Second, if a finite-length beam is fixed at one end and clamped at the other end, and it is subjected to a distributed load $q(x)$ and concentrated force $P$ at $x=x_{0}$, and then the deflection expression is

$$
\begin{aligned}
w= & \sum_{j=1}^{\infty} w_{j} \sin \frac{j \pi x}{L}+\frac{M_{0} L^{2}}{6 E I}\left[\frac{2 x}{L}-3\left(\frac{x}{L}\right)^{2}+\left(\frac{x}{L}\right)^{3}\right] \\
& +\frac{M_{L} L^{2}}{6 E I}\left[\frac{x}{L}-\left(\frac{x}{L}\right)^{3}\right],
\end{aligned}
$$

where $w_{j}, M_{0}$, and $M_{L}$ are undetermined constants.

The uniformly distributed load $q(x)$ is expanded into the following Fourier series:

$$
\begin{aligned}
q(x) & =\sum_{s=1}^{\infty} b_{s} \sin \frac{s \pi}{L} x \\
b_{s} & =\frac{2}{L} \int_{0}^{L} q(x) \sin \frac{s \pi}{L} x \mathrm{~d} x, \quad s=1,2,3, \ldots
\end{aligned}
$$

The concentrated load $P$ is represented by the Dirac delta function, which is expanded into the following Fourier series:

$$
\begin{aligned}
& q^{*}=P \delta\left(x-x_{0}\right), \\
& \delta\left(x-x_{0}\right)=\frac{2}{L} \sum_{t=1}^{\infty} \sin \frac{t \pi x_{0}}{L} \sin \frac{t \pi x}{L}, \quad t=1,2,3, \ldots
\end{aligned}
$$

To compare coefficients, it is necessary to expand $x, x^{2}$, and $x^{3}$ into the Fourier series.

The equations above are substituted into the relevant governing differential equations and boundary conditions, and the algebraic equations for the two boundary conditions can be obtained by comparing the coefficients. The number of equations is the same as the number of undetermined coefficients, so the problem can be solved.

3.2. Iterative Process. An effective iterative technique for solving the problem of a finite-length beam on a Gibson elastic foundation using the refined Vlasov model is detailed as follows: 
Step 1. By assuming an initial approximate value of the attenuation parameter $\gamma_{1}$, the values of the two characteristic parameters $k$ and $G_{p}$ are evaluated using equations (9) and (10).

Step 2. By solving the governing equations (14)-(16) and the corresponding boundary conditions, the deflection values of the beam and foundation can be obtained.

Step 3. By using the solutions for the deflection of the beam and foundation, a new value of $\gamma_{2}$ is computed using formulation (21).

Step 4. The average value of $\gamma_{1}$ and $\gamma_{2}$ is calculated as the new parameter value. The new value of $\gamma_{3}=\left(\gamma_{1}+\gamma_{2}\right) / 2$ is used again to compute new values of the two characteristic parameters $k$ and $G_{p}$.

Step 5. This iterative procedure is repeated until two successive values of $\gamma$ are approximately equal. For example, $\left\|\gamma_{1}-\gamma_{2}\right\| \leq \delta, \delta=0.01$. A program to perform this process is written by using MATLAB.

Principles of solid mechanics are used instead of an experimental or empirical evaluation of the attenuation parameter $\gamma$ and the vertical elastic coefficient $k$ and shear coefficient $G_{p}$. Only the geometric and material characteristics of beams and heterogeneous soils are used to calculate the attenuation parameter iteratively.

\section{Numerical Analysis}

\subsection{Numerical Examples}

Example 1. The refined Gibson foundation model is simplified to the traditional Vlasov elastic foundation. The parameters are the length of the beam $L=10 \mathrm{~m}$, width of the beam $b=1 \mathrm{~m}$, height of the beam $h=0.3 \mathrm{~m}$, elasticity modulus of the beam $E=2.0 \times 10^{10} \mathrm{~N} / \mathrm{m}^{2}$, and Poisson's ratio of the beam $\mu=0.15$. The load $q=400 \mathrm{~N} / \mathrm{m}^{2}$ is a uniformly distributed load applied to the entire beam, and the concentrated force $P=400 \mathrm{kN}$ is applied at the middle of the span. The depth of the soil $H=2 \mathrm{~m}$, elasticity modulus $E_{s}=2.6 \times 10^{7} \mathrm{~N} / \mathrm{m}^{2}$, and Poisson's ratio of $\mu_{s}=0.32$.

When the axial force $F=0$, the attenuation parameter $\gamma=0.39853$ can be obtained using the iterative method. The maximum value of deflection calculated is $4.06 \mathrm{~mm}$, which is consistent with the results in the literature [30]. This demonstrates the correctness of the numerical method.

Example 2. The bending problem of beams with axial forces on a Gibson two-parameter elastic foundation is considered. The parameters to be calculated are the length of the beam $L=10 \mathrm{~m}$, width of the beam $b=1.2 \mathrm{~m}$, height of the beam $h=0.35 \mathrm{~m}$, elasticity modulus of the beam $E=2.4 \times 10^{10} \mathrm{~N} / \mathrm{m}^{2}$, and Poisson's ratio of the beam $\mu=0.16$. The load $q=420 \mathrm{~N} / \mathrm{m}^{2}$ is a uniformly distributed load applied to the entire beam, and the concentrated force $P=360 \mathrm{kN}$ is applied at the middle of the span, and axial force is $F=6000 \mathrm{~N}$, depth of the foundation $H=3 \mathrm{~m}$, elasticity modulus at the bottom of the Gibson soil
$E_{s 2}=3.0 \times 10^{7} \mathrm{~N} / \mathrm{m}^{2}$, and Poisson's ratio of the foundation $\mu_{s}=0.3$.

The calculation results for beams with free ends are listed in Table 1, and the calculation results for beams with one end fixed and the other end clamped are listed in Table 2. In these tables, $w$ refers to the deflection at the centre of a finitelength beam.

When $\eta=0.5$, the deflections and rotation angles of the finite-length beams with one end fixed and the other end clamped are presented in Figures 2 and 3, respectively. Under this condition, the displacements and rotation angles at both ends of the finite-length beam are zero. Additionally, the displacement image is symmetric, and the rotation angle graph is antisymmetric. This is in line with the actual situation, which further proves the applicability of this method. Figures 4-6 present the bending moment diagram, shear force diagram of a finite-length beam, and foundation reaction, respectively. The trends shown in these diagrams agree with the reality.

Further analysis reveals that the inhomogeneity of Gibson foundation soil has a significant influence on the bending behaviour of the elastic layer around the load. The bending deflection of a finite-length beam on a Gibson elastic foundation is mainly affected by the rigidity of the surface soil and less affected by the deep portions of the foundation.

4.2. Iterative Analysis. In Table 3, $N$ represents the number of iterations of the program. $\gamma_{a}$ is the attenuation parameter of a finite-length beam on a traditional Vlasov foundation in Example 1. $\gamma_{b}$ is the attenuation parameter of a beam when both ends are free on a Gibson foundation in Example 2, and $\gamma_{c}$ is the attenuation parameter of a beam when one end is fixed and the other end is clamped on a Gibson foundation in Example 2. The dimensionless parameter of the Gibson foundation is $\eta=0.5$.

\subsection{Sensitivity Analysis}

4.3.1. Axial Force. By observing the deformations and internal forces of the foundation beams under different axial forces (see Figures 7-10), it can be concluded that the existence of axial force makes the midspan deflection, maximum positive and negative bending moment, and rotation angle of the beam increase. The greater the axial force, the greater the increase in amplitude. The axial force also has a certain influence on the shear force of the beam, but the degree of influence varies with the position on the beam. It is reasonable to ignore the influence of the axial force on the peak shear force in engineering calculations. However, the influence of axial force on shear force should not be ignored at positions near the two beam ends.

4.3.2. Gibson Foundation. It can be seen from Figures 11-14 that when the modulus ratio $\eta$ of a Gibson foundation increases, the two parameters $k$ and $G_{p}$ increase, while the bending deflection decreases. And, the elastic modulus of the 
TABLE 1: Calculation results for beams with free ends on a Gibson elastic foundation in Example 2.

\begin{tabular}{lcccc}
\hline $\begin{array}{l}\text { Parameters } \\
\eta\end{array}$ & $\gamma$ & $k\left(10^{7}\left(\mathrm{~N} / \mathrm{m}^{3}\right)\right)$ & $G_{p}\left(10^{7}(\mathrm{~N} / \mathrm{m})\right)$ & $w(\mathrm{~mm})$ \\
\hline $1 / 2$ & 0.62105 & 1.1899 & 0.8191 & 4.185 \\
1 & 0.62106 & 1.6204 & 1.3171 & 3.113 \\
2 & 0.62106 & 2.4812 & 2.3133 & 2.108 \\
\hline
\end{tabular}

TABLE 2: Calculation results for beams with one end fixed and the other end camped on a Gibson foundation in Example 2.

\begin{tabular}{lcccc}
\hline $\begin{array}{l}\text { Parameters } \\
\eta\end{array}$ & $\gamma$ & $k\left(10^{7}\left(\mathrm{~N} / \mathrm{m}^{3}\right)\right)$ & $G_{p}\left(10^{7}(\mathrm{~N} / \mathrm{m})\right)$ & $w(\mathrm{~mm})$ \\
\hline $1 / 2$ & 0.6211 & 1.1896 & 0.8182 & 2.932 \\
1 & 0.6211 & 1.6205 & 1.3159 & 2.399 \\
2 & 0.6211 & 2.4824 & 2.3113 & 1.790 \\
\hline
\end{tabular}

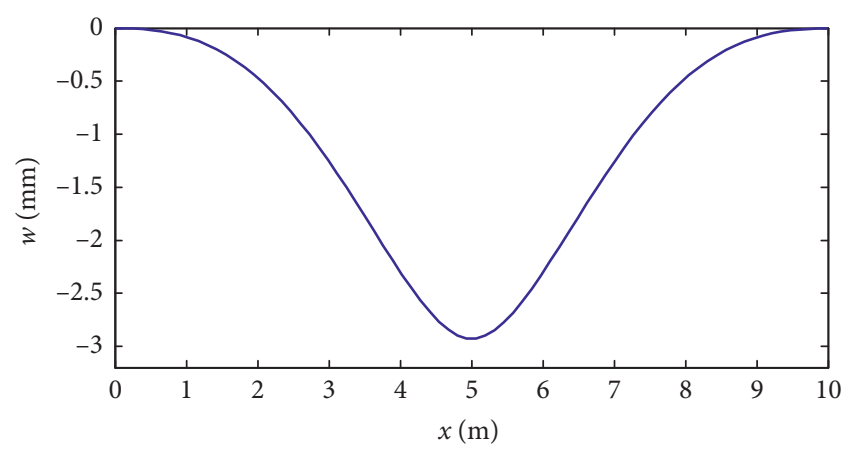

FIGURE 2: Deflection of a beam on a Gibson two-parameter foundation.

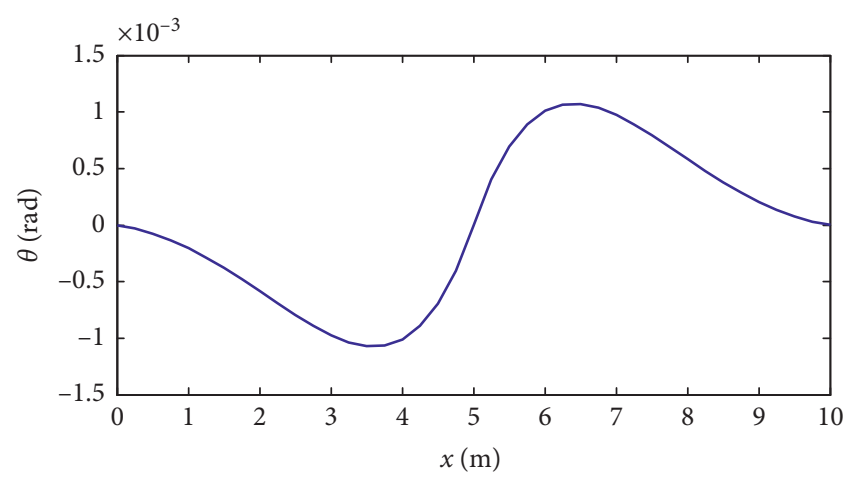

FIGURE 3: Rotation angle of a beam on a Gibson two-parameter foundation.

Gibson foundation soil increases, which causes the two foundation parameters to grow. Therefore, the deformation of the beam and elastic foundation decreases. However, the attenuation parameter remains almost unchanged.

The study also reveals that the harder the surface foundation is, the greater the vertical elastic coefficient $k$ is. This indicates that the vertical elastic coefficient of the foundation is mainly determined by the stiffness of the surface soil. Therefore, to reduce the deflection of

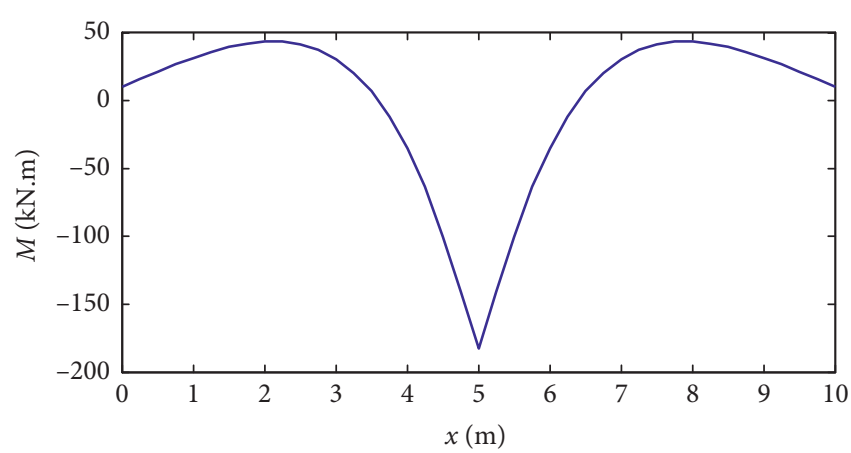

FIgURE 4: Bending moment of a beam on a Gibson two-parameter foundation.

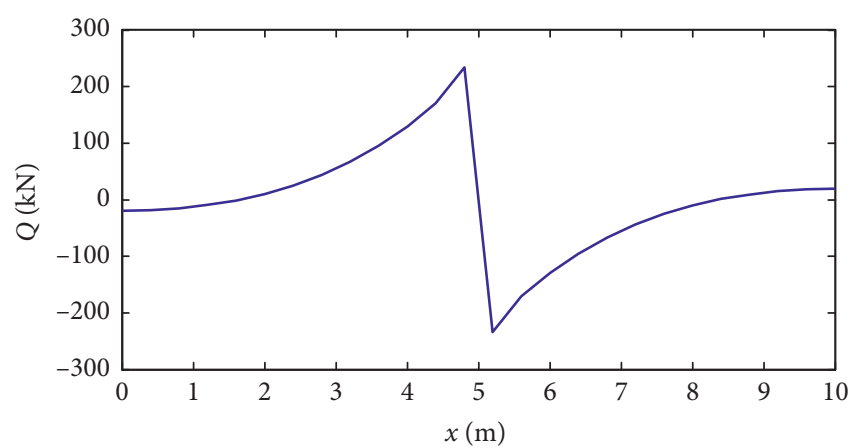

Figure 5: Shear force of a beam on a Gibson two-parameter foundation.

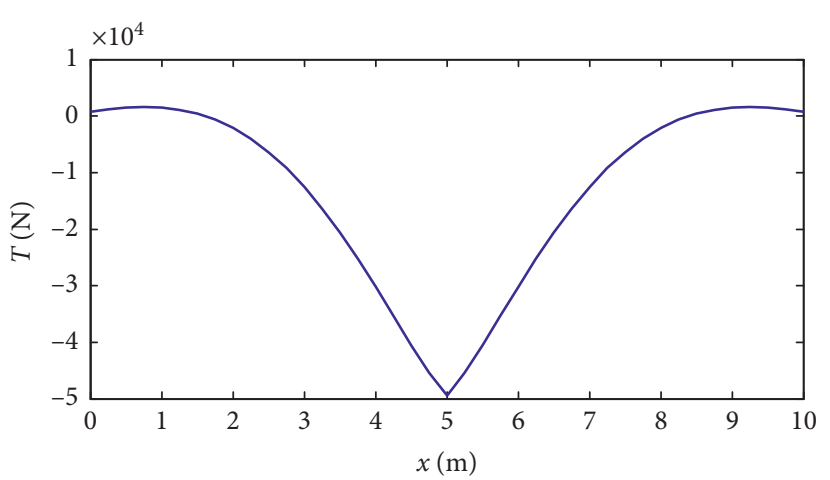

FIgURE 6: Subgrade reaction of a Gibson two-parameter foundation.

foundations in engineering, one can improve the physical properties of foundations at a certain depth under the foundations. However, the effects of strengthening the deep portions of foundations are very limited.

4.3.3. Depth of Foundation. It can be seen from Figures $15-18$ that, with an increase in soil depth, the shear coefficient $G_{p}$, attenuation parameter $\gamma$, and bending deflection $w$ of a finite-length beam at the middle of the span increase, whereas the vertical elastic coefficient $k$ of the foundation decreases.

The further study also reveals that, with an increase in the elastic modulus of a beam, the deflection of a finite-length 
TABLE 3: Attenuation parameters for two-parameter foundations in the examples.

\begin{tabular}{|c|c|c|c|c|c|c|c|c|c|c|c|c|}
\hline$N$ & 0 & 1 & 2 & 3 & 4 & 5 & 6 & 7 & 8 & 9 & 10 & 11 \\
\hline$\gamma_{a}$ & 1.0000 & 0.6993 & 0.5489 & 0.4737 & 0.4361 & 0.4173 & 0.4079 & 0.4032 & 0.4009 & 0.3997 & 0.3991 & 0.3985 \\
\hline$\gamma_{b}$ & 1.0000 & 0.8105 & 0.7158 & 0.6684 & 0.6447 & 0.6329 & 0.6270 & 0.6240 & 0.6225 & 0.6218 & 0.6211 & \\
\hline$\gamma_{c}$ & 1.0000 & 0.8110 & 0.7160 & 0.6680 & 0.6450 & 0.6330 & 0.6270 & 0.6211 & & & & \\
\hline
\end{tabular}

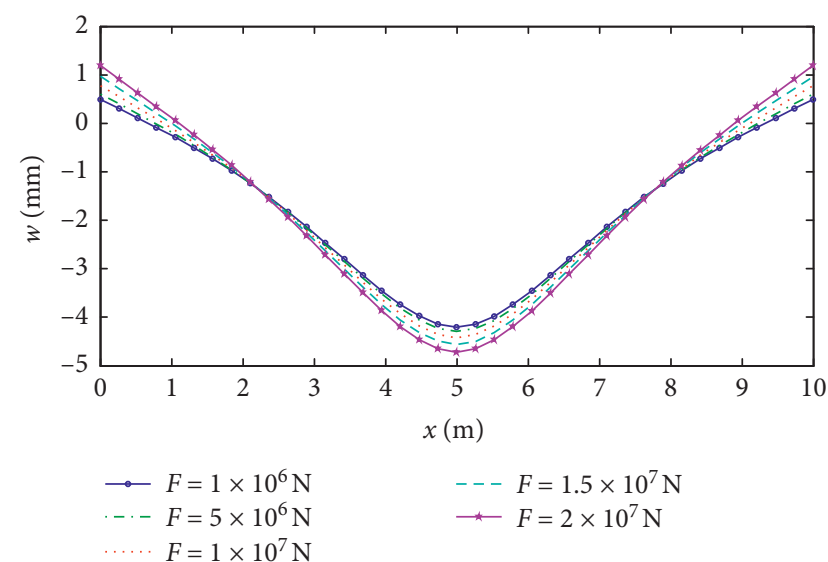

Figure 7: Deflection of finite-length beams with different axial forces.

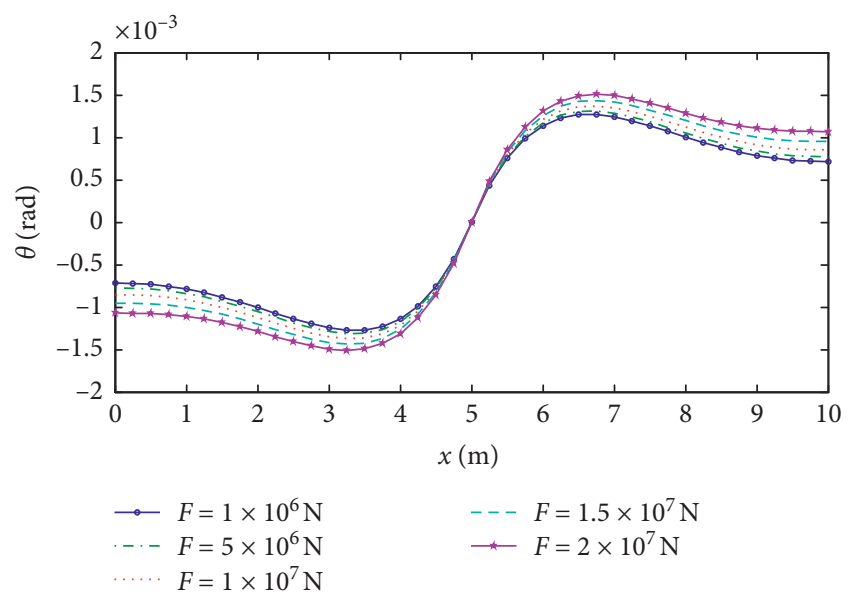

FIGURE 8: Rotation angle of finite-length beams with different axial forces.

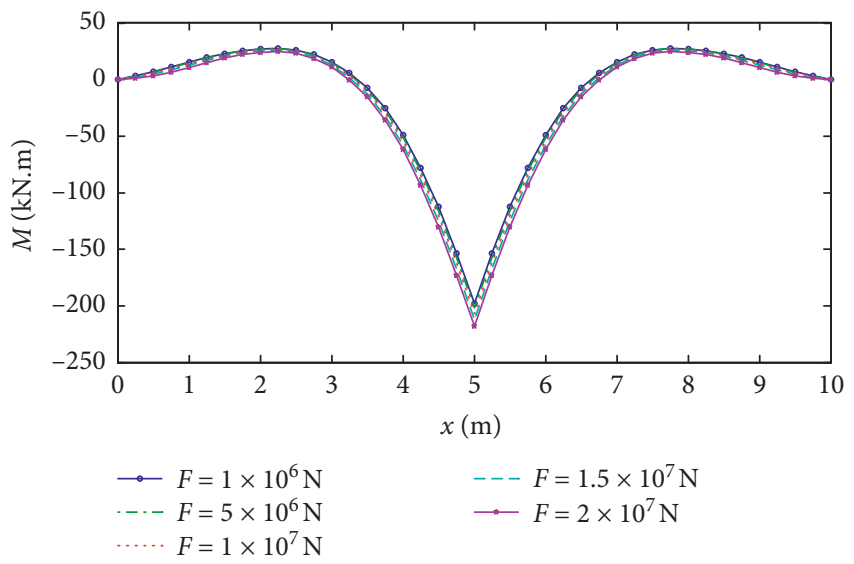

FIGURE 9: Bending moment of finite-length beams with different axial forces.

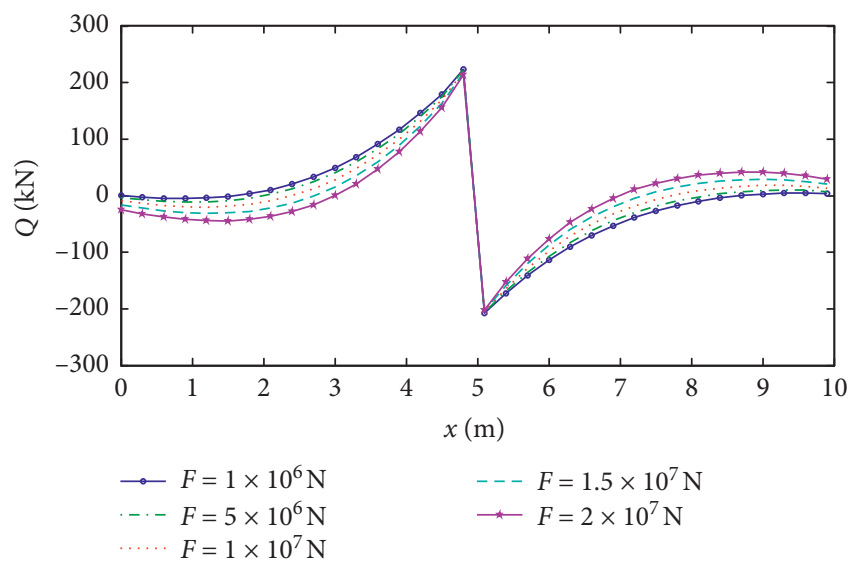

FIGURE 10: Shear force of finite-length beams with different axial forces.

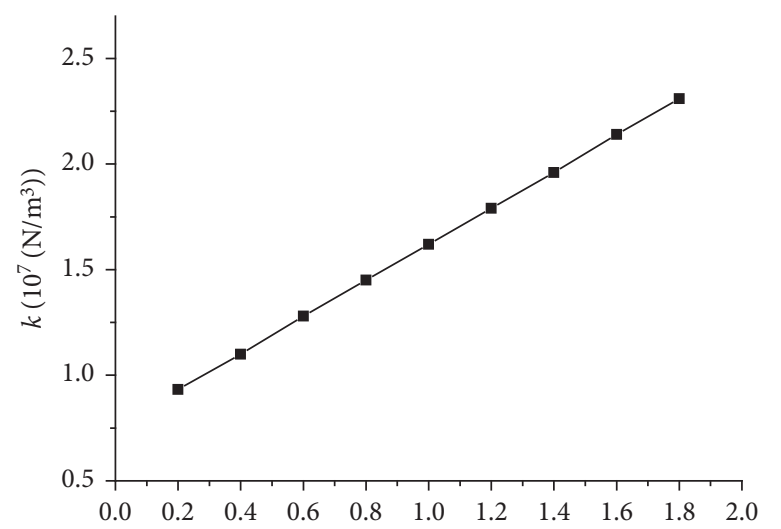

FIgURE 11: Vertical elastic coefficient $k$ for different modulus ratios of the Gibson foundation.

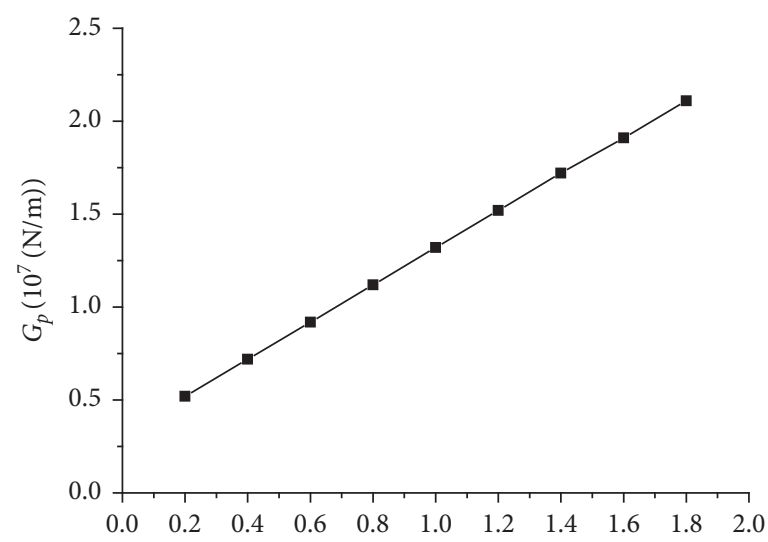

FIgURE 12: Shear coefficient $G_{p}$ for different modulus ratios of the Gibson foundation. 


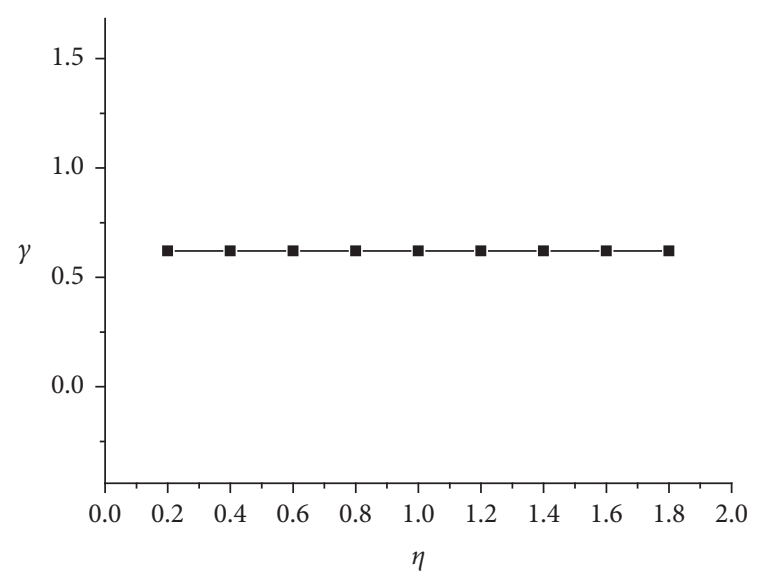

FIGURE 13: Attenuation parameter $\gamma$ for different modulus ratios of the Gibson foundation.

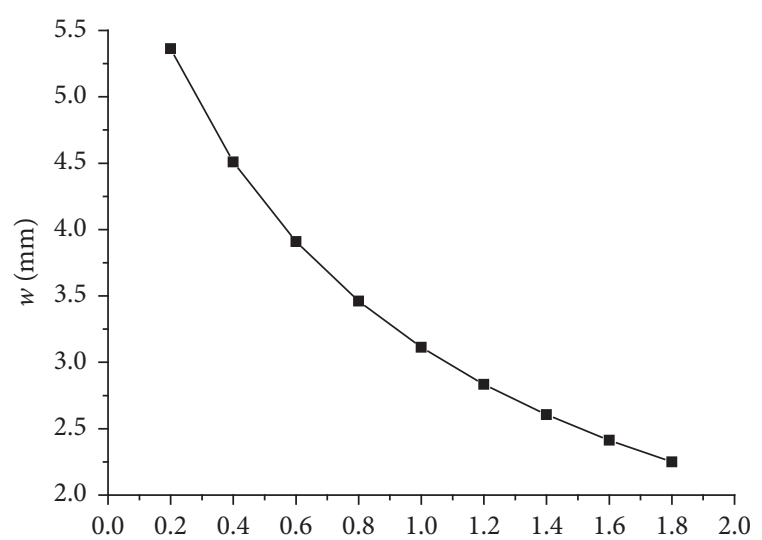

Figure 14: Deflection $w$ of finite-length beams for different modulus ratios of the Gibson foundation.

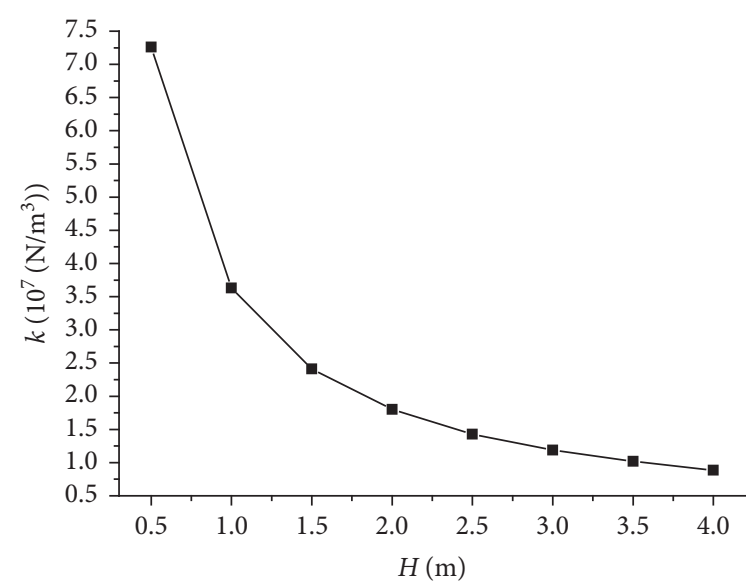

FIGURE 15: Vertical elastic coefficient $k$ for different foundation depths.

beam on elastic foundations decreases. However, the values of the attenuation parameter $\gamma$ and the two model parameters $\left(k, G_{p}\right)$ are almost unchanged. With an increase in the

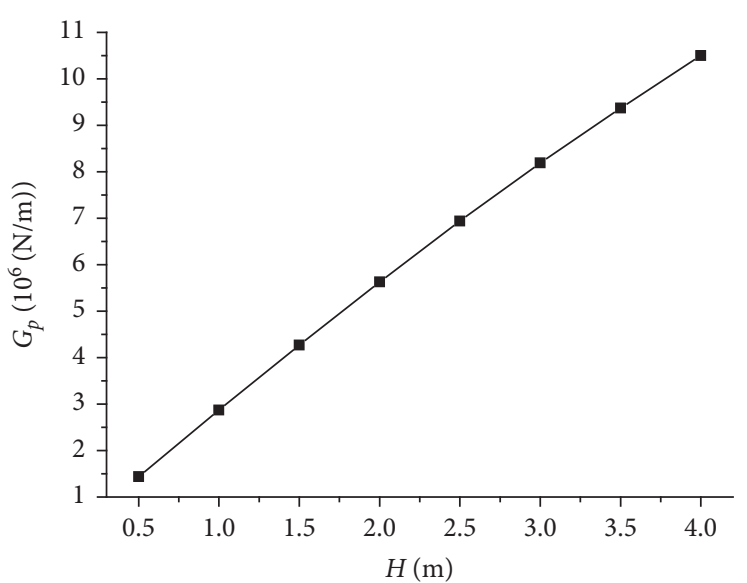

Figure 16: Shear coefficient $G_{p}$ for different foundation depths.

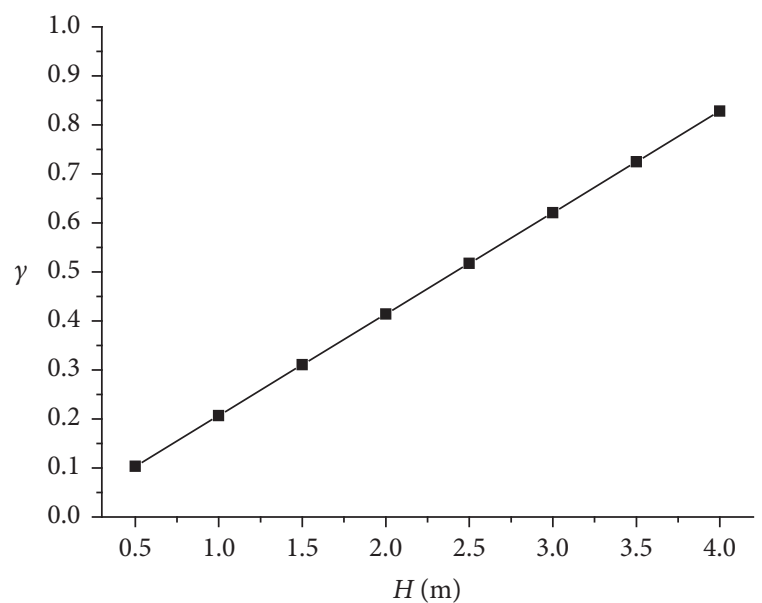

FIgURE 17: Attenuation parameter $\gamma$ for different foundation depths.

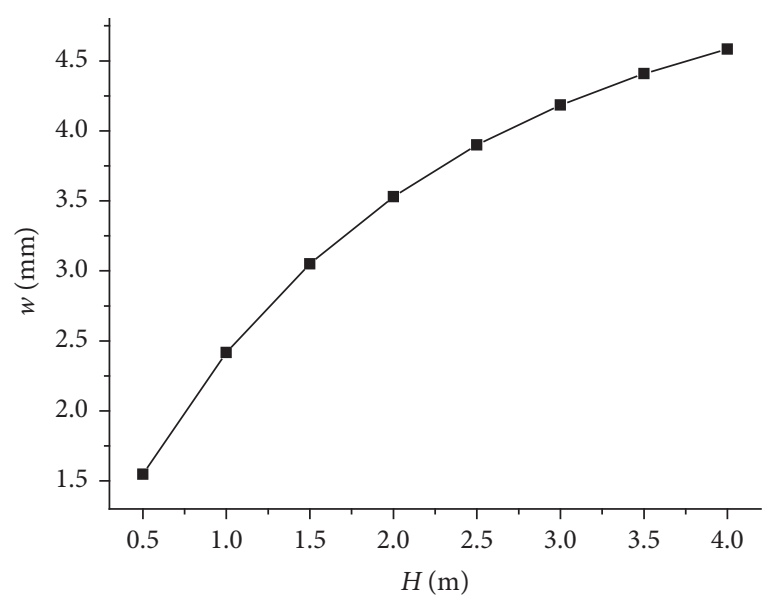

FIGURE 18: Deflection of finite-length beams for different foundation depths.

concentrated force, the deflection of beams on elastic foundations increases exponentially. However, the values of the attenuation parameter and the two model parameters are almost constant. 


\section{Conclusions}

Based on the refined Vlasov elastic foundation model, this paper analyses and solves the bending problem of finitelength beams on elastic Gibson soil foundations. The influences of soil heterogeneity and axial force on beam bending behaviours and foundation characteristic parameters are also investigated. Some conclusions can be drawn based on the numerical results.

(1) The work begins with total deformation potential energy of a foundation-beam system. Through theoretical derivation, it is found that there are no differences between the equations for beams on Gibson foundation and those on traditional twoparameter foundation. However, the relevant model parameters change. If the soil of the refined Vlasov foundation was assumed to be a classical homogeneous medium, the results in this study would be degraded to the classical case of finitelength beams on classical Vlasov elastic foundation. Examples are given to demonstrate the practical application of the refined foundation model.

(2) The presence of axial force makes the midspan deflection, maximum bending moment, and rotation angle of a foundation beam increase. Axial force has some influences on the shear force of a beam. However, the degree of influence varies with the position on the beam. It is feasible to ignore the influence of axial force on the peak shear force in engineering calculations. However, the influence of axial force on shear force cannot be ignored at the positions near the two beam ends.

(3) The Gibson soils have a certain effect on the deflection, internal force, and various characteristic parameters, which should be considered in practice. The results show that the mechanical behaviour of a foundation is mainly determined by the characteristics of the shallow foundation soil under the superstructure, rather than the deep parts of the foundation. In engineering practice, to improve the performance of structural foundations, we can consider enhancing the performance of the shallow portions of foundations.

(4) Considering the properties of Gibson soils, the refined Vlasov foundation model still uses two independent parameters to express the compression and shear properties. For the key attenuation parameter, an iterative method can yield superior results. The characteristics of foundation models do not depend on a certain parameter of soils and structures, but are related to multiple coexisting physical quantities. This indicates that the attenuation parameters derived from experiences or experiments are not accurate and reliable. This paper enriches and expands the content of the Vlasov model and promotes its widespread application.

\section{Data Availability}

All data contained in this study are available upon request from the corresponding author.

\section{Conflicts of Interest}

The author declares no conflicts of interest.

\section{References}

[1] K. Peng, X.-y. Yin, G.-z. Yin, J. Xu, G. Huang, and Z.-q. Yin, "Galerkin solution of Winkler foundation-based irregular Kirchhoff plate model and its application in crown pillar optimization," Journal of Central South University, vol. 23, no. 5, pp. 1253-1263, 2016.

[2] A. Rouabhia, A. Chikh, A. A. Bousahla et al., "Physical stability response of a SLGS resting on viscoelastic medium using nonlocal integral first-order theory," Steel and Composite Structures, vol. 37, no. 6, pp. 695-709, 2020.

[3] N. Bendenia, M. Zidour, A. A. Bousahla et al., "Deflections, stresses and free vibration studies of FG-CNT reinforced sandwich plates resting on Pasternak elastic foundation," Computres and Concrete, vol. 26, no. 3, pp. 213-226, 2020.

[4] M. Rabhi, K. H. Benrahou, A. Kaci et al., "A new innovative 3unknowns HSDT for buckling and free vibration of exponentially graded sandwich plates resting on elastic foundations under various boundary conditions," Geomechanics and Engineering, vol. 22, no. 2, pp. 119-132, 2020.

[5] F. Bourada, A. A. Bousahla, A. Tounsi et al., "Stability and dynamic analyses of SW-CNT reinforced concrete beam resting on elastic-foundation," Computres and Concrete, vol. 25, no. 6, pp. 485-495, 2020.

[6] S. C. Chikr, A. Kaci, A. A. Bousahla et al., "A novel fourunknown integral model for buckling response of FG sandwich plates resting on elastic foundations under various boundary conditions using Galerkin's approach," Geomechanics and Engineering, vol. 21, no. 5, pp. 471-487, 2020.

[7] M. Kaddari, A. Kaci, A. A. Bousahla et al., "A study on the structural behaviour of functionally graded porous plates on elastic foundation using a new quasi-3D model: bending and free vibration analysis," Computres and Concrete, vol. 25, no. 1, pp. 37-57, 2020.

[8] F. Y. Addou, M. Meradjah, A. A. Bousahla et al., "Influences of porosity on dynamic response of FG plates resting on Winkler/Pasternak/Kerr foundation using quasi 3D HSDT," Computres and Concrete, vol. 24, no. 4, pp. 347-367, 2019.

[9] B. Kímençe and M. E. Ergüven, "Interaction between cylindrical and shallow spherical shells on the vlasov model foundation," Computers \& Structures, vol. 45, no. 1, pp. 41-51, 1992.

[10] C. Hizal and H. H. Catal, "Comparative dynamic analysis of axially loaded beams on modified Vlasov foundation," Structural Engineering and Mechanics, vol. 57, no. 6, pp. 969-988, 2016.

[11] A. G. Arani and M. H. Zamani, "Bending analysis of agglomerated carbon nanotube-reinforced beam resting on two parameters modified Vlasov model foundation," Indian Journal of Physics, vol. 92, no. 6, pp. 767-777, 2018.

[12] M. Ataman, "Impact of vlasov foundation parameters on the deflection of a non-uniform Timoshenko beam subject to a moving load," Periodica Polytechnica Civil Engineering, vol. 63, no. 3, pp. 709-717, 2019. 
[13] K. Ozgan, "Dynamic analysis of thick plates including deep beams on elastic foundations using modified Vlasov model," Shock and Vibration, vol. 20, no. 1, pp. 29-41, 2013.

[14] T. Nogami and M. W. O’Neill, "Beam on generalized twoparameter foundation," Journal of Engineering Mechanics, vol. 111, no. 5, pp. 664-679, 1985.

[15] R. Höller, M. Aminbaghai, L. Eberhardsteiner et al., "Rigorous amendment of Vlasov's theory for thin elastic plates on elastic Winkler foundations, based on the Principle of Virtual Power," European Journal of Mechanics - A/Solids, vol. 73, pp. 449-482, 2019.

[16] Y. Ayvaz and A. Daloglu, "Earthquake analysis of beams resting on elastic foundations by using a modified Vlasov model," Journal of Sound and Vibration, vol. 200, no. 3, pp. 315-325, 1997.

[17] Y. Miao, Y. Shi, G. Wang, and Y. Zhong, "Closed-form solution of beam on Pasternak foundation under inclined dynamic load," Acta Mechanica Solida Sinica, vol. 30, no. 6, pp. 596-607, 2017.

[18] J. P. Dempsey and H. Li, "A flexible rectangular footing on a Gibson soil: required rigidity for full contact," International Journal of Solids and Structures, vol. 32, no. 3-4, pp. 357-373, 1995.

[19] R. Salgado, H. Seo, and M. Prezzi, "Variational elastic solution for axially loaded piles in multilayered soil," International Journal for Numerical and Analytical Methods in Geomechanics, vol. 37, no. 4, pp. 423-440, 2013.

[20] M. Eisenberger and J. Clastornik, "Beams on variable twoparameter elastic foundation," Journal of Engineering $\mathrm{Me}$ chanics, vol. 113, no. 10, pp. 1454-1466, 1987.

[21] C. Medina, G. M. Álamo, J. J. Aznárez, L. A. Padrón, and O. Maeso, "Influence of soil non-homogeneity on the base shear force of piled structures subjected to harmonic seismic waves," Engineering Structures, vol. 215, Article ID 110658, 2020.

[22] J. J. Ma, Q. J. Liu, and Y. Y. Zhao, "Stability of beams on modified Vlasov foundation subjected to lateral loads acting on the ends," Chinese Journal of Geotechnical Engineering, vol. 30, no. 6, pp. 850-854, 2008.

[23] C. V. G. Vallabhan, W. T. Straughan, and Y. C. Das, "Refined model for analysis of plates on elastic foundations," Journal of Engineering Mechanics, vol. 117, no. 12, pp. 2830-2844, 1991.

[24] R. Jones and J. Xenophontos, "On the Vlasov and Kerr foundation models," Acta Mechanica, vol. 25, no. 1-2, pp. $45-49,1976$.

[25] T. Y. Yang, "A finite-element analysis of plates on a twoparameter foundation model," Computers \& Structures, vol. 2, no. 4, pp. 593-614, 1972.

[26] Q. J. Liu, Y. Y. Zhao, and J. J. Ma, "The stability of beam on elastic layered Gibson foundation," Engineering Mechanics, vol. 26, no. 2, pp. 48-52, 2009.

[27] C. V. G. Vallabhan and Y. C. Das, "A refined model for beams on elastic foundations," International Journal of Solids and Structures, vol. 27, no. 5, pp. 629-637, 1991.

[28] C. V. G. Vallabhan and Y. C. Das, "Parametric study of beams on elastic foundations," Journal of Engineering Mechanics, vol. 114, no. 12, pp. 2072-2082, 1988.

[29] C. V. G. Vallabhan and Y. C. Das, "Modified Vlasov model for beams on elastic foundations," Journal of Geotechnical Engineering, vol. 117, no. 6, pp. 956-966, 1991.

[30] Y. Huang and F. S. He, Beams, Plates, and Shells on Elastic Foundations, pp. 36-39, Science Press, Beijing, China, 2005. 